\title{
Early estimates of influenza vaccine effectiveness in Navarre, Spain: 2012/13 mid-season analysis
}

J Castilla (jcastilc@navarra.es) ${ }^{1,2}$, I Martínez-Baz ${ }^{1,2}$, V Martínez-Artola 3 , M Fernandez-Alonso4, G Reina ${ }^{4}$, M Guevara ${ }^{1,2}$, M García Cenoz $^{1,2}$, F Elía ${ }^{5}$, N Alvarez ${ }^{6}$, A Barricarte ${ }^{1,2}$, C Ezpeleta $^{3}$

1. Instituto de Salud Pública de Navarra (Public Health Institute of Navarre), Pamplona, Spain

2. Centro de Investigación Biomédica en Red de Epidemiología y Salud Pública (CIBERESP; Network of Biomedical Research Centers Epidemiology and Public Health), Spain

3. Complejo Hospitalario de Navarra (Hospital Complex of Navarre), Pamplona, Spain

4. Clínica Universidad de Navarra (University Clinic of Navarre), Pamplona, Spain

5. Primary Healthcare Directorate, Navarre Health Service, Pamplona, Spain

6. Servicio Navarro de Salud (Navarre Health Service), Pamplona, Spain

Citation style for this article:

Castilla J, Martínez-Baz I, Martínez-Artola V, Fernandez-Alonso M, Reina G, Guevara M, García Cenoz M, Elía F, Alvarez N, Barricarte A, Ezpeleta C. Early

estimates of influenza vaccine effectiveness in Navarre, Spain: 2012/13 mid-season analysis. Euro Surveill. 2013;18(7):pii=20404. Available online: http://www. eurosurveillance.org/ViewArticle. aspx?Articleld=2040

Article published on 14 february 2013

We present estimates of influenza vaccine effectiveness (VE) in Navarre, Spain, in the early 2012/13 season, which was dominated by influenza B. In a population-based cohort using electronic records from physicians, the adjusted VE in preventing influenzalike illness was 32\% (95\% confidence interval (CI): 15 to 46 ). In a nested test-negative case-control analysis the adjusted VE in preventing laboratory-confirmed influenza was $86 \%$ ( $95 \% \mathrm{Cl}: 45$ to 96$)$. These results suggest a high protective effect of the vaccine.

\section{Background}

In the 2012/13 influenza season the composition recommended for the influenza vaccine in the northern hemisphere included $A / C a l i f o r n i a / 07 / 2009\left(\mathrm{H}_{1} \mathrm{~N}_{1}\right)$ pdmo9-like, A/Victoria/361/2011 $\left(\mathrm{H}_{3} \mathrm{~N}_{2}\right)$-like and $\mathrm{B} /$ Wisconsin/1/2010(Yamagata)-like viruses [1].

During the early $2012 / 13$ season, influenza B virus was the predominant circulating influenza virus in Spain, and most characterised isolates belonged to the $B /$ Yamagata lineage [2]. The aim of this study was to provide early estimates of the effectiveness of the $2012 / 13$ seasonal vaccine in preventing medically-attended influenza-like illness (MA-ILI) and laboratory-confirmed influenza in Navarre, Spain.

\section{Estimating influenza vaccine effectiveness}

The effectiveness of the influenza vaccine varies every season. Estimates of vaccine effectiveness (VE) during the influenza season help guide health interventions aimed at reducing the impact of influenza in the population [3,4]. A multi-centre European study (I-MOVE: Influenza Monitoring Vaccine Effectiveness in Europe)

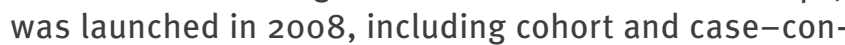
trol studies in several settings and the work presented here for Navarre is part of this project $[3,4]$.
We conducted a prospective cohort study based on electronic records of physicians and laboratories and a nested case-control analysis of swabbed patients in Navarre, between 5 November 2012 (week 45 of 2012 - the first week in which influenza virus was detected more than 14 days after the beginning the vaccination campaign) and 3 February 2013 (week 5 of 2013). This cohort included all persons covered by the Regional Health Service, except healthcare workers, persons living in nursing homes and children under six months of age ( $96 \%$ of the population of the region).

The seasonal influenza vaccination campaign took place from 15 October to 30 November 2012. The trivalent inactivated non-adjuvanted vaccine (Sanofi Pasteur MSD) was offered free of charge to people aged 60 or over and to those with major chronic conditions. Other people can also be vaccinated if they pay for the vaccine. Precise instructions for registering each dose of vaccine were communicated to all vaccination sites [5]. Influenza vaccine status was obtained from the online regional vaccination register [6]. Subjects were considered to be protected 14 days after vaccine administration.

Influenza surveillance was based on automatic reporting of cases of influenza-like illness (ILI) from all primary healthcare physicians and searching of ILI cases by public health nurses in hospitals. All of them followed the European Union case definition [7]. A sentinel network composed of a representative sample of 79 primary healthcare physicians, covering $16 \%$ of the population, was requested to take nasopharyngeal and pharyngeal swabs, after obtaining verbal informed consent from all their patients diagnosed with ILI, whose symptoms had begun preferably less than five days previously. In hospitals, an agreed protocol for influenza cases was applied, which specified early detection and nasopharyngeal and pharyngeal 


\section{FIGURE}

Weekly incidence of medically-attended influenza-like illness and number of swabbed patients according to influenza virus test result, Navarre, Spain, 1 October 2012-3 February 2013

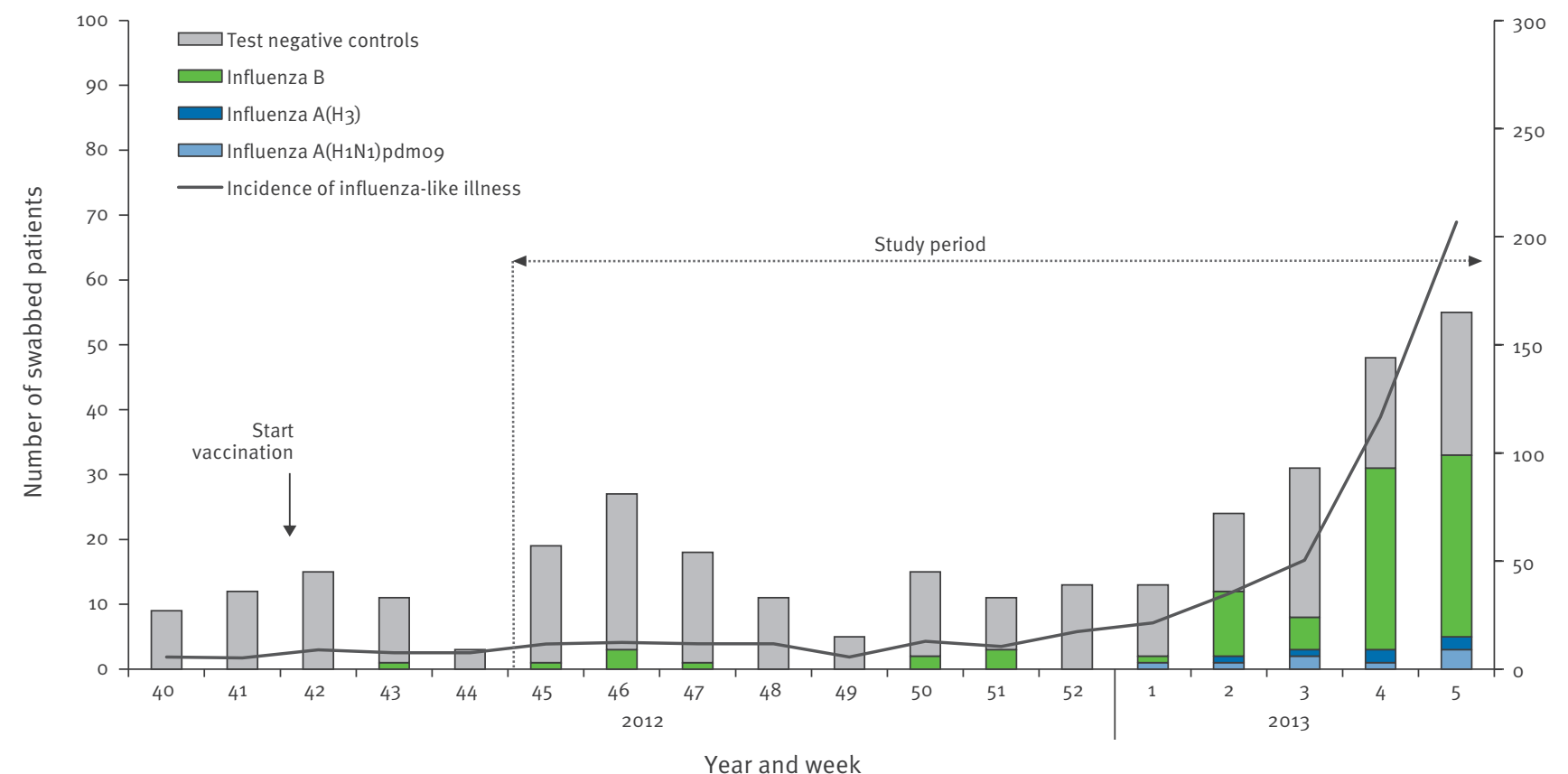

\section{TABLE 1}

Estimates of the effect of the seasonal influenza vaccine in preventing medically-diagnosed influenza-like illness, Navarre, Spain, 5 November 2012-3 February 2013

\begin{tabular}{|c|c|c|c|c|c|c|}
\hline & Person-years & Cases of MA-ILI & $\begin{array}{l}\text { Crude vaccine } \\
\text { effectiveness, \% } \\
(95 \% \mathrm{Cl})\end{array}$ & $P$ value & $\begin{array}{l}\text { Adjusted vaccine } \\
\text { effectiveness, \% } \\
(95 \% \mathrm{CI})^{\mathrm{a}}\end{array}$ & P value \\
\hline \multicolumn{7}{|c|}{ Weeks $45 / 2012$ to $5 / 2013^{b}$} \\
\hline \multicolumn{7}{|c|}{ Whole cohort } \\
\hline Unvaccinated & 133,499 & 3,100 & Reference & \multirow{2}{*}{$<0.001$} & Reference & \multirow{2}{*}{$<0.001$} \\
\hline Vaccinated & 20,043 & 189 & $56(46$ to 64$)$ & & 32 (15 to 46$)$ & \\
\hline \multicolumn{7}{|c|}{ Target population ${ }^{c}$} \\
\hline Unvaccinated & 37,870 & 737 & Reference & \multirow{2}{*}{$<0.001$} & Reference & \multirow{2}{*}{0.004} \\
\hline Vaccinated & 17,889 & 144 & $59(51$ to 65$)$ & & 32 (11 to 48$)$ & \\
\hline \multicolumn{7}{|c|}{ Weeks 1 to $5 / 2013^{d}$} \\
\hline \multicolumn{7}{|c|}{ Whole cohort } \\
\hline Unvaccinated & 50,526 & 2,517 & Reference & \multirow{2}{*}{$<0.001$} & Reference & \multirow{2}{*}{$<0.001$} \\
\hline Vaccinated & 8,436 & 143 & $66(60$ to 71$)$ & & 30 (15 to 42$)$ & \\
\hline \multicolumn{7}{|c|}{ Target population $^{c}$} \\
\hline Unvaccinated & 13,903 & 553 & Reference & \multirow{2}{*}{$<0.001$} & Reference & \multirow{2}{*}{0.004} \\
\hline Vaccinated & 7,498 & 108 & $64(55$ to 71$)$ & & $30(12$ to 44$)$ & \\
\hline
\end{tabular}

MA-ILI: medically-attended influenza-like illness.

a Poisson regression model adjusted for sex, age (10-year groups), major chronic conditions, primary healthcare visits during the previous year (tertiles), hospitalisation in the previous year, urban/rural area, migrant status, children in the household and month.

b Whole study period which corresponds to the period between 5 November 2012 and 3 February 2013.

c Target population for vaccination includes people $\geq 60$ years-old and people with major chronic conditions.

d Period with increasing incidence of MA-ILI. 
swabbing of all hospitalised patients with ILI. Swabs were processed by reverse transcription-polymerase chain reaction (RT-PCR) assay, and samples positive for $A\left(\mathrm{H}_{1} \mathrm{~N}_{1}\right)$ pdmo9, $A\left(\mathrm{H}_{3}\right)$ and $B$ virus were identified.

From the electronic primary healthcare records we obtained the following baseline variables: sex, age, migrant status, district of residence, major chronic conditions (heart disease, lung disease, renal disease, cancer, diabetes mellitus, cirrhosis, dementia, stroke, immunodeficiency, rheumatic disease and body mass

\section{TABLE 2}

Characteristics of laboratory-confirmed influenza cases $(n=97)$ and test-negative controls $(n=194)$, Navarre, Spain, 5 November 2012-3 February 2013

\begin{tabular}{|c|c|c|c|}
\hline & $\begin{array}{c}\text { Laboratory- } \\
\text { confirmed } \\
\text { influenza } \\
\text { cases }\end{array}$ & $\begin{array}{c}\text { Test- } \\
\text { negative } \\
\text { controls }\end{array}$ & $P$ value \\
\hline & $\mathrm{n}(\%)$ & $\mathrm{n}(\%)$ & \\
\hline \multicolumn{3}{|l|}{ Age groups (years) } & $<0.001$ \\
\hline$<5$ & $3(3)$ & $30(15)$ & \\
\hline $5-14$ & $28(29)$ & $29(15)$ & \\
\hline $15-44$ & $38(39)$ & $66(34)$ & \\
\hline $45-64$ & $26(27)$ & $43(22)$ & \\
\hline$\geq 65$ & $2(2)$ & $26(13)$ & \\
\hline \multicolumn{3}{|l|}{ Sex } & 0.901 \\
\hline Male & $48(49)$ & $98(51)$ & \\
\hline Female & $49(51)$ & $96(49)$ & \\
\hline \multicolumn{3}{|l|}{ Residence } & 0.384 \\
\hline Rural & $20(21)$ & $50(26)$ & \\
\hline Urban & 77 (79) & $144(74)$ & \\
\hline \multicolumn{3}{|l|}{ Migrant status } & 0.521 \\
\hline No & $90(93)$ & $174(90)$ & \\
\hline Yes & $7(7)$ & $20(10)$ & \\
\hline \multicolumn{3}{|l|}{ Major chronic conditions } & 0.044 \\
\hline No & $66(68)$ & $108(56)$ & \\
\hline Yes & $31(32)$ & $86(44)$ & \\
\hline \multicolumn{3}{|c|}{ Hospitalisation in the previous year } & $<0.001$ \\
\hline No & $92(95)$ & $148(76)$ & \\
\hline Yes & $5(5)$ & $46(24)$ & \\
\hline \multicolumn{3}{|c|}{ Outpatient visits in the previous year } & $<0.001$ \\
\hline o to 5 & $60(62)$ & $73(38)$ & \\
\hline$>5$ & $37(38)$ & $121(62)$ & \\
\hline \multicolumn{3}{|l|}{ Healthcare setting } & $<0.001$ \\
\hline Primary healthcare & $88(91)$ & $118(61)$ & \\
\hline Hospitalisation & $8(8)$ & $68(35)$ & \\
\hline Emergency rooms & $1(1)$ & $8(4)$ & \\
\hline \multicolumn{3}{|l|}{ Period } & $<0.001$ \\
\hline Weeks $45 / 2012$ to $52 / 2012$ & $10(10)$ & $109(56)$ & \\
\hline Weeks $1 / 2013$ to $5 / 2013$ & $87(89)$ & $85(44)$ & \\
\hline \multicolumn{3}{|c|}{ Seasonal influenza vaccine $2012 / 13$} & $<0.001$ \\
\hline No & $94(97)$ & $157(81)$ & \\
\hline Yes & $3(3)$ & 37 (19) & \\
\hline Total & $97(100)$ & $194(100)$ & \\
\hline
\end{tabular}

index $\geq 40 \mathrm{~kg} / \mathrm{m} 2$ ), hospitalisation in the previous 12 months, primary healthcare visits in the previous 12 months, and children in the household.

\section{Cohort analysis}

The incidence rates of MA-ILI were compared in vaccinated and unvaccinated persons. Person-years were used as the denominator, with end of follow-up at the date of MA-ILI diagnosis, death, or 3 February 2013 (end of this analysis), whichever came first. Poisson regression models were used to obtain MA-ILI-adjusted rate ratios for influenza vaccination status.

Test-negative case-control analysis

All outpatients and hospitalised patients who were swabbed during the study period were included in a case-control analysis that compared seasonal vaccination status in patients in whom any influenza virus was detected (cases) and those who were negative for influenza (controls). Crude and adjusted estimators of the effect were quantified by odds ratios (ORs) with their $95 \%$ confidence intervals (Cls), calculated using logistic regression models. The adjusted models included age group $(45,5-14,15-44,45-64$ and $\geq 65$ years), major chronic conditions, three-week periods (weeks 45 to 47 of 2012, 48 to 50 of 2012, 51 of 2012 to 1 of 2013, 2 to 4 of 2013 and 5 of 2013) and healthcare setting (primary healthcare, emergency room and hospitalisation), because these were the statistically significant variables in the bivariate analyses and altered the OR by $3 \%$ or more. Separated analyses were done by type of influenza, by healthcare setting, for patients for whom influenza vaccination was indicated because they were 60 years of age or older or had some major chronic condition, and for patients diagnosed in the period of increasing incidence (weeks 1 to 5 of 2013).

Percentages were compared by chi-squared test and Fisher's exact test. VE was estimated as a percentage: $(1-$ rate ratio $) \times 100$ or $(1-0 R) \times 100$.

\section{Mid 2012/13 season influenza vaccine effectiveness}

Vaccine effectiveness in preventing medicallyattended influenza-like illness

A total of 616,721 persons were included in the cohort study, of which 223,936 had an indication for vaccination because they were 60 years of age or older or had some major chronic condition. The influenza vaccine coverage was $14.2 \%$ in the whole cohort and $49.4 \%$ in subjects aged 60 years or more.

From week 45 of 2012 to week 5 of $2013,3,289$ cases of MA-ILI were diagnosed, with an increasing incidence in the last weeks (Figure).

The MA-ILI incidence rate was 9.4 per 1,000 vaccinated person-years as opposed to 23.2 per 1,000 unvaccinated person-years ( $p<0.001)$, and the adjusted VE against MA-ILI was $32 \%$ ( $95 \% \mathrm{Cl}: 15$ to 46 ). In the target 
population for vaccination the incidence rate was 8.0 per 1,000 vaccinated person-years and 19.5 per 1,000 unvaccinated person-years ( $p<0.001$ ), and the adjusted VE against MA-ILI was $32 \%(95 \% \mathrm{Cl}: 11$ to 48$)$. When the analyses were restricted to the period with increasing MA-ILI incidence (weeks 1 to 5 of 2013), the estimates were similar (Table 1).

\section{Vaccine effectiveness in preventing laboratory- confirmed influenza \\ During the study period, $291 \mathrm{ILI}$ patients were swabbed of whom 97 (33\%) were confirmed for influenza virus: $83(86 \%)$ for influenza $B$, eight for influenza $A\left(\mathrm{H}_{1} \mathrm{~N}_{1}\right)$ pdmog and six for influenza $\mathrm{A}\left(\mathrm{H}_{3}\right)$ virus (Figure). All swabs from outpatients had been taken in the first five days after symptom onset.}

Compared with confirmed cases of influenza, the group of test-negative controls had a higher proportion of persons under the age of five years or 65 years and older, persons with major chronic conditions, people who had consulted a physician five or more times in the past year, who had been hospitalised in the past year, and who were treated in the hospital (Table 2).
There were three ( $3 \%$ ) laboratory-confirmed cases in the 97 patients who had received the $2012 / 13$ seasonal vaccine, while 37 (19\%) of the 194 influenza-negative controls had received the influenza vaccine ( $p<0.001$ ). In the logistic regression analysis, the adjusted estimate of the influenza VE was $86 \%$ ( $95 \% \mathrm{Cl}: 45$ to 96 ). The comparison of influenza B cases with controls gave similar results ( $89 \% ; 95 \% \mathrm{Cl}: 46$ to 98 ), while the estimate of the VE in preventing influenza A cases had a wide confidence interval $(68 \% ; 95 \% \mathrm{Cl}:-189$ to 99). Other analyses restricted to the period between weeks 1 and 5 of 2013, to the target population for vaccination or including only primary healthcare patients also found high VE (Table 3). All 14 type B viruses with known lineage were $B / Y a m a g a t a$, which was the same lineage included in the vaccine. Two vaccine failures were due to influenza $B$ and happened in persons with some immunodepression, and one vaccine failure was due to influenza $A\left(\mathrm{H}_{1} \mathrm{~N}_{1}\right)$ pdmog virus in an immunocompetent person.

\section{Discussion and conclusion}

The early estimates of this study show a high protective effect of the 2012/13 seasonal influenza vaccine in preventing laboratory-confirmed cases of influenza

TABLE 3

Influenza vaccine effectiveness in preventing laboratory-confirmed influenza in Navarre, Spain, 5 November 2012-3 February 2013

\begin{tabular}{|c|c|c|c|c|c|}
\hline & Cases; controls & $\begin{array}{l}\text { Crude vaccine } \\
\text { effectiveness, \% } \\
(95 \% \mathrm{Cl})\end{array}$ & $P$ value & $\begin{array}{l}\text { Adjusted vaccine } \\
\text { effectiveness, \% } \\
\qquad(95 \% \mathrm{Cl})^{\mathrm{a}}\end{array}$ & P value \\
\hline \multicolumn{6}{|c|}{ All swabbed patients } \\
\hline Unvaccinated & $94 ; 157$ & Reference & \multirow{2}{*}{0.001} & Reference & \multirow{2}{*}{0.005} \\
\hline Vaccinated & $3 ; 37$ & $86(55$ to 96$)$ & & $86(45$ to 96$)$ & \\
\hline \multicolumn{6}{|c|}{ Primary healthcare patients } \\
\hline Unvaccinated & $85 ; 105$ & Reference & \multirow{2}{*}{0.056} & Reference & \multirow{2}{*}{0.029} \\
\hline Vaccinated & $3 ; 13$ & $71(-3$ to 92$)$ & & $80(15$ to 95$)$ & \\
\hline \multicolumn{6}{|c|}{ Hospitalised patients } \\
\hline Unvaccinated & $8 ; 51$ & Reference & \multirow{2}{*}{0.235} & Reference & \multirow{2}{*}{0.221} \\
\hline Vaccinated & $0 ; 17$ & $72(-98 \text { to } 100)^{b}$ & & $78(-138 \text { to } 100)^{b}$ & \\
\hline \multicolumn{6}{|c|}{ Target population for vaccinationc } \\
\hline Unvaccinated & $32 ; 64$ & Reference & \multirow{2}{*}{0.007} & Reference & \multirow{2}{*}{0.021} \\
\hline Vaccinated & $2 ; 31$ & $87(43$ to 97$)$ & & 88 (28 to 98$)$ & \\
\hline \multicolumn{6}{|c|}{ Weeks 1 to $5 / 2013^{d}$} \\
\hline Unvaccinated & $84 ; 66$ & Reference & \multirow{2}{*}{0.001} & Reference & \multirow{2}{*}{0.004} \\
\hline Vaccinated & $3 ; 19$ & 88 (56 to 96$)$ & & 88 (49 to 97) & \\
\hline \multicolumn{6}{|l|}{ Influenza B } \\
\hline Unvaccinated & $81 ; 157$ & Reference & \multirow{2}{*}{0.002} & Reference & \multirow{2}{*}{0.007} \\
\hline Vaccinated & $2 ; 37$ & $89(55$ to 97$)$ & & 89 (46 to 98$)$ & \\
\hline \multicolumn{6}{|l|}{ Influenza A } \\
\hline Unvaccinated & $13 ; 157$ & Reference & \multirow{2}{*}{0.470} & Reference & \multirow{2}{*}{0.531} \\
\hline Vaccinated & $1 ; 37$ & $67(-132 \text { to } 99)^{b}$ & & $68(-189 \text { to } 99)^{b}$ & \\
\hline
\end{tabular}

a Logistic regression model adjusted for age group $(\langle 5,5-14,15-44,45-64$ and $\geq 65$ years), three-week periods, major chronic conditions, hospitalisation in the previous year and healthcare setting (primary healthcare, emergency room and hospitalisation).

b Exact logistic regression analysis.

Target population for vaccination includes people $\geq 60$ years-old and people with major chronic conditions.

d Period with increasing incidence of medically-attended influenza-like illness. 
in Navarre and a notable effect against MA-ILI. During the study period influenza $B$ virus was predominantly (86\%) found, and all type B viruses with known lineage were B/Yamagata, which was the same lineage included in the vaccine [1].

Although the estimates overlap, our results might suggest a higher VE in Navarre than obtained in the early estimates in the United States, the United Kingdom, Canada and Denmark for the same season [8-11]. In these studies the proportion of influenza $A$ cases (range: $24-91 \%$ ) was higher than in Navarre (14\%) and Spain (15\%) [2,8-11].

The results presented here are preliminary and may have limited statistical power for some analyses. Therefore the final results for the season may be different. Cohort studies can be affected by biases if those who are vaccinated tend to have poorer health status or if, on the contrary, they tend to take better care of their health than the unvaccinated $[12,13]$, but our analyses were controlled for the most frequently recognised confounders [14]. The case-control analysis included only laboratory-confirmed cases and compared them with controls recruited in the same healthcare settings before either patient or physician knew the laboratory result, a fact that reduced selection bias.

The analyses of VE against two outcomes provide complementary information. The effectiveness of $86 \%$ in preventing laboratory-confirmed influenza can be considered the best estimate of the actual protective effect of the trivalent $2012 / 13$ seasonal vaccine. The effectiveness of $32 \%$ in preventing MA-ILI describes the effect as seen in clinical practice, in which not all ILI cases are confirmed for influenza virus. The consistency of the results obtained using two designs for two different outcomes reinforces their validity.

These results support a high protective effect of the seasonal vaccine against influenza disease in Navarre in the early $2012 / 13$ season where predominantly influenza B circulates and highlight the importance of annual immunisation against influenza of high-risk populations.

\section{Acknowledgements}

This work is part of the Influenza Monitoring Vaccine Effectiveness in Europe (I-MOVE) Network. The members of the Primary Health Care Sentinel Network of Navarre are: I Abad, P Aldaz, E Álvarez, JJ Arana, I Arceiz, E Arina, I Arribas, MD Artajo, A Arza, B Azagra, FC Bartolome, C Bernués, C Bolea, A Brugos, B Cano, MV Castresana, JC Cenoz, F Cia, B Compains, JR Corpas, F Cortés, B Churío, PC Cuevas, EM Da Costa, J Díez Espino, M Doiz, FJ Escribano, MJ Esparza, V Etayo, C Fernández Alfaro, B Flamarique, J Gamboa, ML Garcés, L García Blanco, AB German, A Giner, M Gómara, N Goñi, MJ Guillorme, JO Guiu, JC Gurbindo, MJ Guruchaga, JA Heras, MC Hijos, MS Indurain, B Iñigo, SE Juan Belloc, JJ Jurio, MP León, JJ Longás, JJ Miner, M Moreno, MA Moros, U Navarro, FJ Orozco, M Orte, P Palacio, J Palau, C Pérez Lecumberri, P Pérez Pascual, B Pérez Sanz, A Prado Virto, M
Prado Santamaria, A Puig Arrastia, E Ridruejo, M Ramos, BE Rípodas, M Rodríguez, MA Roncal, I Ruiz Puertas, C Sánchez Vázquez, P Sarrasqueta, MA Senosiain, J Sola, M Sota, ME Ursua, IA Urtasun, MJ Vigata, MT Virto, JM Vizcay.The members of the Network for Influenza Surveillance in Hospitals of Navarre are: P Artajo, E Bernaola, J Chamorro, P Fanlo, F Gil, M Gabari, J Hueto, C Pérez, M Ruiz (Complejo Hospitalario de Navarra), J Núñez (Clínica Universidad de Navarra), JJ García Irure, M Ortega, M Torres (Hospital Reina Sofía, Tudela), F Lameiro, N Navascués (Hospital García Orcoyen, Estella).

\section{Funding}

This work was supported by the Carlos III Institute of Health (PS12/00087), and by the Spanish Ministry of Health (EC11-302).

Conflicts of interest

None declared.

\section{Authors' contributions}

Jesús Castilla, Iván Marínez-Baz, Marcela Guevara, Manuel García Cenoz and Aurelio Barricarte, designed the study and coordinated the activities. Iván Marínez-Baz, Marcela Guevara and Jesús Castilla undertook the statistical analysis. Fernando Elía and Nerea Alvarez prepared the electronic databases. Víctor Martínez-Artola, Mirian Fernández-Alonso, Gabriel Reina and Carmen Ezpeleta were responsible of the virological analysis and the interpretation of laboratory results. Jesús Castilla, Iván Marínez-Baz, Marcela Guevara wrote the draft manuscript, and all authors revised and approved the final version.

\section{References}

1. Recommended composition of the influenza virus vaccines for use in the 2012-2013 northern hemisphere influenza season. Wkly Epidemiol Rec. 2012;87(10):83-95. PMid:22462202

2. Sistema de Vigilancia de la Gripe en España. Informe semanal 5/2013. [Report of the influenza surveillance system in Spain 5/2013]. Madrid: Instituto de Salud Carlos III; 7 Feb 2013. № 337. Spanish. Available from: http://vgripe.isciii.es/gripe/ documentos/20122013/boletines/grno513.pdf

3. Valenciano $M$, Ciancio BC, Moren A, the influenza vaccine effectiveness working group. First steps in the design of a system to monitor vaccine effectiveness during seasonal and pandemic influenza in EU/EEA Member States. Euro Surveill. 2008;13(43):pii=19015. Available from: http:// www.eurosurveillance.org/ViewArticle.aspx?Articleld $=19015$ PMid:18947520

4. Valenciano M, Ciancio B, on behalf of the I-MOVE study team. I-MOVE: a European network to measure the effectiveness of influenza vaccines. Euro Surveill, 2012;17(39):pii=20281. Available from: http://www.eurosurveillance.org/ViewArticle. aspx?Articleld $=20281$

5. Instituto de Salud Pública de Navarra. Protocolo de vacunación antigripal 2012-2013 [Influenza vaccination protocol 20122013]. Boletín Informativo. 2012;69. Spanish. Available from: http://www.navarra.es/NR/rdonlyres/AECCD760-AB2A-4841818A-FA53478FD6DC/233865/BOL69INT2012_2013.pdf

6. Aguilar I, Reyes M, Martínez-Baz I, Guevara M, Albéniz E, Belza MJ, et al. Use of the vaccination register to evaluate influenza vaccine coverage in seniors in the 2010/11 influenza season, Navarre, Spain. Euro Surveill. 2012;17(17): pii=20154. Available from: http://www.eurosurveillance.org/ViewArticle. aspx?Articleld=20154 PMid:22551499

7. European Commission. Commission Decision of 28 April 2008 amending Decision 2002/253/EC laying down case definitions for reporting communicable diseases to the Community network under Decision No 2119/98/EC of the European Parliament and of the Council. Official Journal of the European Union. Luxembourg: Publications Office of the European Union. 18.6.2008:L 159/46. Available from: http://eur-lex.europa.eu/ 
LexUriServ/LexUriServ.do?uri=0J:L:2008:159:0046:0090:EN: PDF

8. Centers for Disease Control and Prevention (CDC). Early estimates of seasonal influenza vaccine effectiveness United States, January 2013. MMWR Morb Mortal Wkly Rep. 2013;62:32-5. PMid:23325354

9. McMenamin J, Andrews N, Robertson C, Fleming DM, Durnall $H$, von Wissmann B, et al. Effectiveness of seasonal 2012/13 vaccine in preventing laboratory-confirmed influenza infection in primary care in the United Kingdom: mid-season analysis 2012/13. Euro Surveill. 2013;18(5): $\mathrm{pii}=20393$.

Available from: http://www.eurosurveillance.org/ViewArticle. aspx?Articleld $=20393$

10. Skowronski DM, Janjua NZ, De Serres G, Dickinson JA, Winter A, Mahmud SM, et al. Interim estimates of influenza vaccine effectiveness in 2012/13 from Canada's sentinel surveillance network, January 2013. Euro Surveill. 2013;18(5): pii=20394. Available from: http://www.eurosurveillance.org/ViewArticle. aspx?Articleld=20394 PMid:23399422

11. Bragstad K, Emborg HD, Kølsen Fischer T, Voldstedlund M, Gubbels S, Andersen B, et al. Low vaccine effectiveness against influenza $\mathrm{A}\left(\mathrm{H}_{3} \mathrm{~N}_{2}\right)$ virus among elderly people in Denmark in 2012/13 - a rapid epidemiological and virological assessment. Euro Surveill. 2013;18(6):pii=20397. Available from: http://www.eurosurveillance.org/ViewArticle. aspx?Articleld $=20397$

12. Simonsen L, Taylor RJ, Viboud C, Miller MA, Jackson LA. Mortality benefits of influenza vaccination in elderly people: an ongoing controversy. Lancet Infect Dis. 2007;7(10):658-66. http://dx.doi.org/10.1016/S1473-3099(07)70236-0

13. Jackson LA, Jackson ML, Nelson JC, Neuzil KM, Weiss NS. Evidence of bias in estimates of influenza vaccine effectiveness in seniors. Int J Epidemiol. 2006;35(2):337-44 . http://dx.doi. org/10.1093/ije/dyi274 PMid:16368725

14. Valenciano M, Kissling E, Ciancio BC, Moren A. Study designs for timely estimation of influenza vaccine effectiveness using European sentinel practitioner networks. Vaccine. 2010;28(46):7381-8.http://dx.doi.org/10.1016/j. vaccine.2010.09.010 PMid:20851086 